\title{
Simulation of Land Surface Climate over China with RegCM4.5: Verification and Analysis
}

\author{
Minghao Yang $\left(\mathbb{D},{ }^{1}\right.$ Ruiting Zuo ${ }^{D},{ }^{1}$ Liqiong Wang, ${ }^{1,2}$ and Xiong Chen $\mathbb{D}^{1}$ \\ ${ }^{1}$ College of Meteorology and Oceanography, National University of Defense Technology, Nanjing 211101, China \\ ${ }^{2}$ Nanjing Star-Jelly Environmental Consultants Co. Ltd., Nanjing 210013, China \\ Correspondence should be addressed to Ruiting Zuo; ratinzuo@126.com
}

Received 29 November 2017; Accepted 13 February 2018; Published 3 April 2018

Academic Editor: Anthony R. Lupo

Copyright (c) 2018 Minghao Yang et al. This is an open access article distributed under the Creative Commons Attribution License, which permits unrestricted use, distribution, and reproduction in any medium, provided the original work is properly cited.

\begin{abstract}
The ability of RegCM4.5 using land surface scheme CLM4.5 to simulate the physical variables related to land surface state was investigated. The NCEP-NCAR reanalysis data for the period 1964-2003 were used to drive RegCM4.5 to simulate the land surface temperature, precipitation, soil moisture, latent heat flux, and surface evaporation. Based on observations and reanalysis data, a few land surface variables were analyzed over China. The results showed that some seasonal features of land surface temperature in summer and winter as well as its magnitude could be simulated well. The simulation of precipitation was sensitive to region and season. The model could, to a certain degree, simulate the seasonal migration of rainband in East China. The overall spatial distribution of the simulated soil moisture was better in winter than in summer. The simulation of latent heat flux was also better in winter. In summer, the latent heat flux bias mainly arose from surface evaporation bias in Northwest China, and it primarily arose from vegetation evapotranspiration bias in South China. In addition, the large latent heat flux bias in South China during summer was probably due to less precipitation generated in the model and poor representation of vegetation cover in this region.
\end{abstract}

\section{Introduction}

A regional climate model (RCM) usually has a higher resolution than a general circulation model (GCM); thus, it can better resolve the interaction between the atmosphere and land surface and effectively capture regional forcing, such as large bodies of water, surface vegetation, and complex topography which have a significant impact on local climate $[1,2]$. Therefore, RCMs are among the most promising tools to simulate climate on the regional scale [3]. Based on BATS (Biosphere and Atmospheric Transfer System) and CLM3.5 (Community Land Model version 3.5), CLM4.5 (Community Land Model version 4.5) was developed and added as one of the land surface options for RegCM4.5 (Regional Climate Model version 4.5) which was released in 2016 [4]. As one of the important components of the climate system, land surface is a crucial surface of the atmospheric motion and has substantial influences on weather and climate change $[5,6]$. Sometimes, it may even play a critical role in atmospheric circulation in some local region.
Using RegCM series of models, a great number of numerical simulations have been carried out in recent decades. Most of these studies focused on verifying the model capability for climate simulation, future climate projection, model sensitivity test, extreme climate events simulation, or examining some specific physical processes [7-11]. Giorgi [1] first conducted one-month numerical simulation over the western US with RegCM1, and he found that the model can successfully simulate the spatial distribution of temperature and precipitation. Aiming at exploring the interaction between orographic precipitation and the large-scale monsoon circulation, Wang and Chang [12] used RegCM3 to simulate the summer monsoon onset in South and Southeast Asia during the year 2000. Marcella and Eltahir [13] used RegCM3 to analyze surface temperature, surface albedo, short wave incident radiation, and water vapor pressure over Southwest Asia region and studied the role of land surface process in climate formation in semiarid regions. Using RegCM3, Zhang and Shi [14] obtained projected future climate in North China. They analyzed future change of temperature, precipitation, and extreme weather. Gao et al. [15] used 
RegCM4.4 to evaluate several rivers in China and found that the model can reproduce the climatological means, trends, and extremes very well. It should be noted that the regional climate modeling approach has been proved to be useful for improving our understanding of many climate processes, such as cloud-radiation forcing, cumulus convection, and land surface processes [16-18].

For studies related to land surface physics, Zou and Xie [19] compared the impact of different land surface schemes on East Asia climate by applying CLM3.5 and BATS in RegCM4 model for sensitivity test. Wang et al. [20] used RegCM4 to study the effects of different land surface schemes on precipitation simulation in the Tibetan Plateau. They found that the choice of land surface scheme had a significant impact on the simulation results. Some other researchers used RegCM2 and the high-resolution Regional Climate Model of the National Climate Center (RegCM-NCC) of China to study how vegetation cover change influences the future climate in China. The results indicate that the change of vegetation cover can modify the local circulation through its impact on the exchange of energy between the land and the atmosphere; consequently, precipitation and temperature are also modified due to the change of local circulation [21]. Compared with CLM3.5, a lot of changes have been made in parametrization schemes in CLM4.5 [22]. While representation of land surface is crucial in an atmospheric model, significant differences exist regarding the performance of the CLM series of models [23]. Several studies showed that the selection of a land surface scheme has a substantial impact on the simulation of the climate models $[20,24]$, but there is no study evaluating the capability of RegCM4.5 coupled with CLM4.5, especially about the simulation of land surface physical variables. What about the ability of RegCM4.5 coupled with CLM4.5 to simulate land surface climate over China? This study is motivated by this gap, and we believe the result of this study can provide an important reference for future research with RegCM4.5 and CLM4.5. Besides, it may provide a good alternative option for future researchers when they need to study the regional land surface climate over China.

It has been found that RCMs exhibit different skill levels for different regions [25]. In the present study, NCEP-NCAR reanalysis data are used to drive RegCM4.5 to simulate the climate over China during the period 1964-2003. Based on reanalysis data, the simulation using RegCM4.5 coupled with CLM4.5 can be evaluated by analyzing the simulated land surface temperature, precipitation, soil moisture, latent heat flux, and surface evaporation with a few statistical parameters such as correlation coefficient, root mean square error (RMSE), and difference between simulation and observations (bias). The organization of the rest of this paper is as follows. An introduction to the model and experiments is described in Section 2. The description of the simulation results is given in Section 3, and the conclusions are given in Section 4.

\section{Model and Experimental Design}

2.1. RegCM. In 1989, the first-generation regional climate model RegCM1 was developed based on MM4 (Mesoscale
TABLE 1: List of physical parameterization schemes used in simulation.

\begin{tabular}{lc}
\hline Physical process & Scheme \\
\hline Cumulus convection over land & Emanuel \\
Cumulus convection over ocean & Emanuel \\
Large-scale precipitation & SUBEX \\
Radiation & CCM3 \\
Land surface & CLM4.5 \\
Lateral boundary & Index relaxation \\
Planetary boundary layer & Holtslag \\
Air-sea flux & Zeng scheme \\
Pressure gradient & Hydrostatic deduction \\
\hline
\end{tabular}

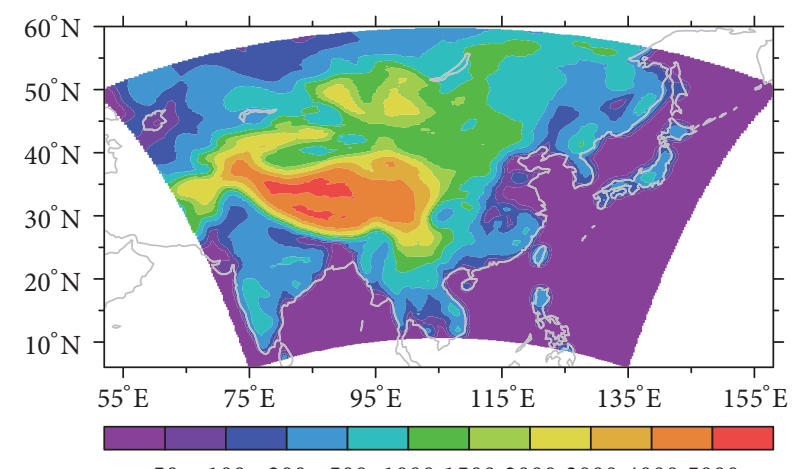

$50 \quad 100200 \quad 500100015002000300040005000$

FIGURE 1: Model domain and terrain height (unit: $\mathrm{m}$ ).

Model version 4). After nearly all the physical schemes were upgraded by Giorgi and his team, the RegCM2 was released in 1993. The RegCM3 and RegCM4 were released in 2006 and 2010, respectively. The version used in this study is RegCM4.5 (http://gforge.ictp.it/gf/project/regcm/) which was released in May 2016. Compared with previous versions, the most significant upgrade is (1) the implementation of land surface model CLM4.5; (2) adoption of MM5 nonhydrostatic dynamical core; (3) upgrade of the terrain data from USGS (United States Geological Survey) GTOPO to USGS-NGA (National Geospatial-Intelligence Agency) GMTED which has higher vertical resolution; and (4) adding an option for aerosols.

2.2. Experiments. The model has a horizontal resolution of $60 \mathrm{~km}$ and a $\sigma$ vertical coordinate system of 18 levels with the top level of $5 \mathrm{hPa}$. The domain for the experiment is over China and the center is at $35^{\circ} \mathrm{N}, 105^{\circ} \mathrm{E}$. The grid numbers in east-west and north-south directions are 128 and 96 (the domain is shown in Figure 1). Our tests suggest that the Emanuel scheme is better for cumulus convection over both land and ocean, which is consistent with a previous study [23]. The hydrostatic dynamical core is used in the model dynamic framework, and the adopted physical parameterization schemes are listed in Table 1 . The simulation period is 1964-2003. As the land surface climate is our focus, we consider the period 1964-1983 as model spin-up time. The winter is defined from December to next February for the 


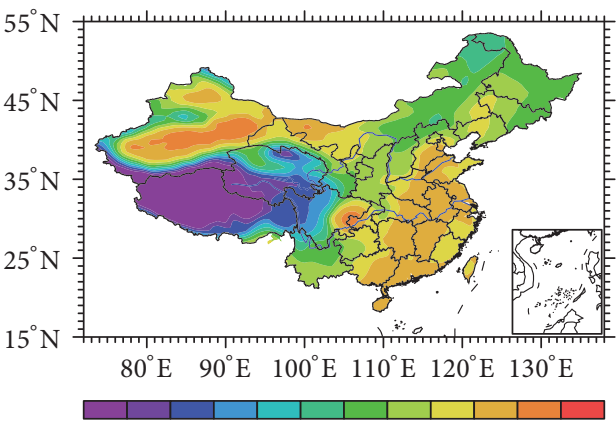

$\begin{array}{lllllllllll}3 & 6 & 9 & 12 & 15 & 18 & 21 & 24 & 27 & 30 & 33\end{array}$

(a)

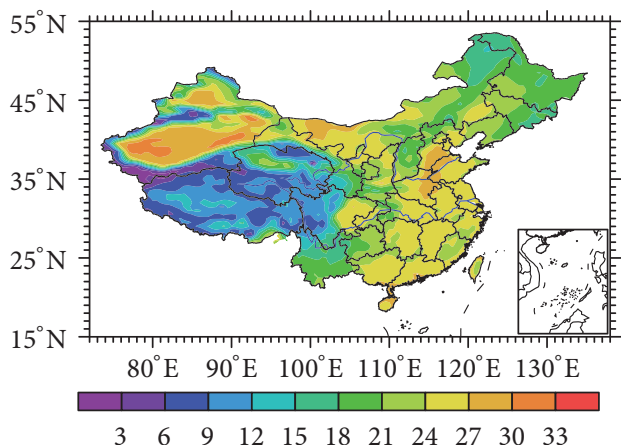

(c)

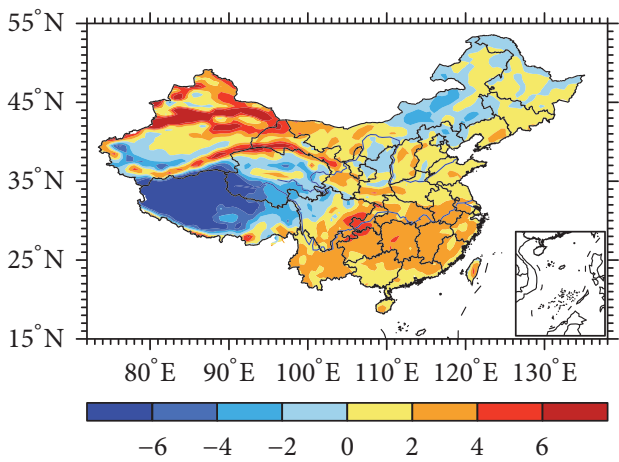

(e)

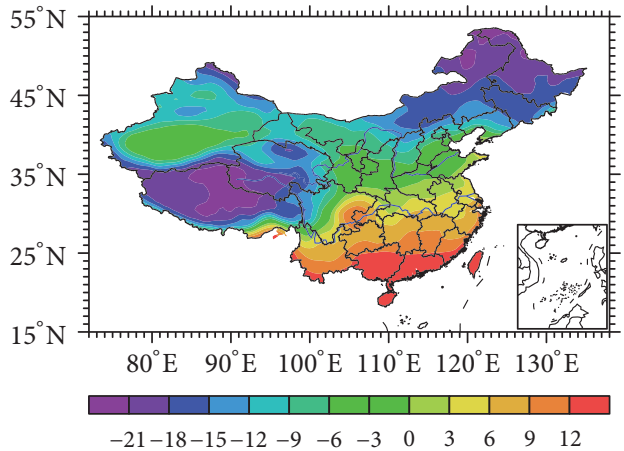

(b)

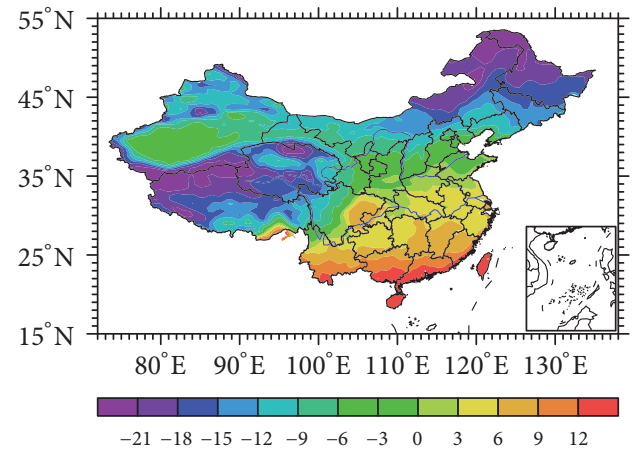

(d)

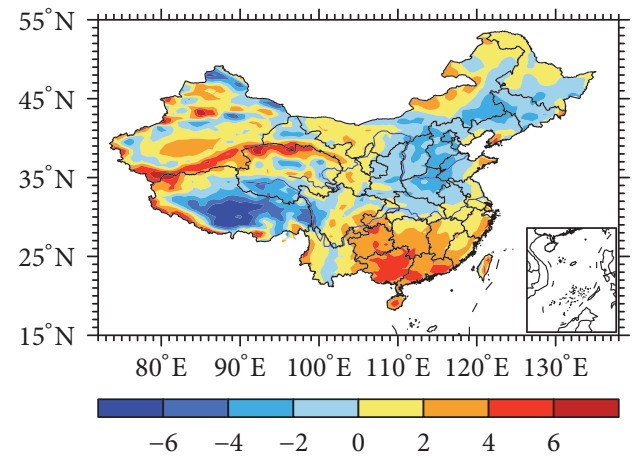

(f)

FIgURE 2: Mean land surface temperature over China (unit: ${ }^{\circ}$ C). (a) Simulation in summer, (b) simulation in winter, (c) reanalysis in summer, (d) reanalysis in winter, (e) difference between simulation and reanalysis in summer, and (f) difference between simulation and reanalysis in winter.

period 1983-2002, and the summer is defined from June to August during the period 1984-2003.

2.3. Data. The initial and lateral boundary data for the model are from the NCAR/NCEP reanalysis. The SST (Sea Surface Temperature) data are from NOAA (National Oceanic and Atmospheric Administration) monthly mean dataset, and the terrain data are from GMTED. The default PFT (Plant Functional Types) data (MODIS) for RegCM4.5 are used, with a horizontal resolution of $0.25^{\circ} \times 0.25^{\circ}$. The observations of precipitation are from CN05.1 dataset, which is a set of grid data constructed based on more than 2400 surface observation stations in China [26]. Reanalysis data include CFSR (Climate Forecast System Reanalysis) land surface temperature, soil moisture, latent heat flux, and surface evaporation, as well as NASA (National Aeronautics and Space Administration) GLDAS (Global Land Data Assimilation System) soil moisture data.

\section{Results and Discussion}

3.1. Land Surface Temperature. Figure 2 shows the mean land surface temperature in summer and winter over China from reanalysis, simulation, and their differences. By comparing Figure 2(a) with Figure 2(c), we can easily find that the spatial distribution of land surface temperature in China during summer is well simulated. The pattern correlation coefficient and RMSE are 0.93 and $3.2^{\circ} \mathrm{C}$, respectively. The centers of the 
TABLE 2: Bias, RMSE, and pattern correlation coefficients of simulated precipitation.

\begin{tabular}{|c|c|c|c|c|}
\hline & & Bias $(\mathrm{mm})$ & RMSE (mm) & Correlation coefficient \\
\hline \multirow{7}{*}{ Summer } & North China & 108.4 & 182.6 & -0.41 \\
\hline & Northeast China & -19.6 & 55.9 & 0.65 \\
\hline & East China & -79.5 & 175.9 & -0.38 \\
\hline & South China & -219.0 & 219.7 & 0.68 \\
\hline & Southwest China & 29.0 & 208.6 & 0.24 \\
\hline & Northwest China & 29.9 & 61.7 & 0.90 \\
\hline & Plateau & -90.9 & 175.9 & 0.57 \\
\hline \multirow{7}{*}{ Winter } & North China & 20.7 & 21.1 & 0.87 \\
\hline & Northeast China & 21.9 & 20.3 & 0.59 \\
\hline & East China & -36.9 & 66.4 & 0.89 \\
\hline & South China & -96.2 & 105.5 & 0.66 \\
\hline & Southwest China & 8.8 & 40.4 & 0.49 \\
\hline & Northwest China & 18.3 & 24.7 & 0.59 \\
\hline & Plateau & 21.6 & 30.4 & 0.09 \\
\hline
\end{tabular}

simulated maximum and minimum land surface temperature are generally consistent with the observations. According to Figure 2(e), it can be seen that the simulated land surface temperature in summer still has large bias over some regions; for instance, large warm bias of more than $4^{\circ} \mathrm{C}$ can be found over the Tian Shan Mountains and the Kunlun Mountains and near the Sichuan Basin, while large cold bias of more than $6^{\circ} \mathrm{C}$ exists over the Tibetan Plateau. Nevertheless, the bias over most other regions is less than $3^{\circ} \mathrm{C}$; particularly, there is generally no bias over Northeast China and North China. The comparison between Figures 2(b) and 2(d) indicates that the model can successfully reproduce some primary features of wintertime climate over China, such as large temperature gradient over the land and nearly west-east orientated contours of temperature in Central-East China and South China. It is also obvious (Figure 2(f)) that the difference is smaller in winter than in summer, and the corresponding RMSE and correlation coefficient are $2.6^{\circ} \mathrm{C}$ and 0.99 , respectively, though large warm bias can be found in South China. The model overall has better performance in simulating land surface temperature in winter than in summer.

3.2. Precipitation. For convenience, we adopted a classification of climatic zone in China from $\mathrm{Li}$ and Ding [27]: Northeast China $\left(40^{\circ} \mathrm{N}-50^{\circ} \mathrm{N}, 120^{\circ} \mathrm{E}-130^{\circ} \mathrm{E}\right)$, North China $\left(35^{\circ} \mathrm{N}-40^{\circ} \mathrm{N}, 110^{\circ} \mathrm{E}-120^{\circ} \mathrm{E}\right)$, East China $\left(27^{\circ} \mathrm{N}-35^{\circ} \mathrm{N}\right.$, $\left.110^{\circ} \mathrm{E}-120^{\circ} \mathrm{E}\right)$, South China $\left(18^{\circ} \mathrm{N}-25^{\circ} \mathrm{N}, \quad 107^{\circ} \mathrm{E}-120^{\circ} \mathrm{E}\right.$, mainly including Guangdong, Guangxi, and Hainan provinces), Southwest China $\left(25^{\circ} \mathrm{N}-35^{\circ} \mathrm{N}, 100^{\circ} \mathrm{E}-110^{\circ} \mathrm{E}\right)$, Northwest China $\left(37^{\circ} \mathrm{N}-42^{\circ} \mathrm{N}, 90^{\circ} \mathrm{E}-110^{\circ} \mathrm{E}\right)$, and Plateau Zone $\left(30^{\circ} \mathrm{N}-35^{\circ} \mathrm{N}, \quad 90^{\circ} \mathrm{E}-100^{\circ} \mathrm{E}\right)$. Table 2 lists the correlation coefficient, RMSE, and difference between the observations and simulations in each climatic zone during summer and winter. Figure 3 shows the observed and simulated mean precipitation in China during summer and winter. For the simulation of summertime precipitation, the RMSE and the correlation between observations and simulation are $196.3 \mathrm{~mm}$ and 0.68, respectively. Comparing Figure 3(a) with
Figure 3(c), we can find that the simulated summertime precipitation is close to observations in Northeast China and Northwest China. From Table 2, we learn that the difference between the simulated and observed precipitation over Northeast China in summer is $-19.6 \mathrm{~mm}$, and the corresponding RMSE and correlation coefficient are $55.9 \mathrm{~mm}$ and 0.85 , respectively. For Northwest China, the difference between the simulated and observed precipitation, RMSE, and correlation coefficients are $29.9 \mathrm{~mm}, 61.7 \mathrm{~mm}$, and 0.90 , respectively. This reveals that the model has better capability in simulating summertime precipitation in Northeast China and Northwest China than other climatic zones.

However, the model failed to reproduce the aspect that precipitation over the southeast monsoon region is much more than that over the regions in the north during summer. The negative bias in South China is as large as $219.0 \mathrm{~mm}$; as a result, another aspect that precipitation over some regions in South China is more than $750 \mathrm{~mm}$ is also not found in the simulation. Besides, in North China, a large positive bias of $108.4 \mathrm{~mm}$ and RMSE of $182.6 \mathrm{~mm}$ are also facts of unsatisfactory simulation. On the other hand, due to the lack of observations, the model tends to produce large biases in a broad area over the Tibetan Plateau. Because of the effect of large-scale topography, the model generated a spurious center of maximum precipitation over the Tibetan Plateau, which is consistent with the simulations conducted with previous versions of the model. This also accounts for the worse simulation of summertime precipitation pattern over Southwest China, with a correlation coefficient of 0.24. For wintertime precipitation, the correlation between the simulated and observed values is 0.30 , and the RMSE is $59.4 \mathrm{~mm}$. If we compare the patterns of the simulated and observed precipitation (Figures 3(b) and 3(d)), we can notice that the model can generally simulate the location of maximum precipitation. The correlation coefficient for East China is as large as 0.89 , and improvement is also obvious in Southwest China. The bias and RMSE over North China are $20.7 \mathrm{~mm}$ and $21.1 \mathrm{~mm}$, which both are less compared with those of summertime simulation. However, the simulation 


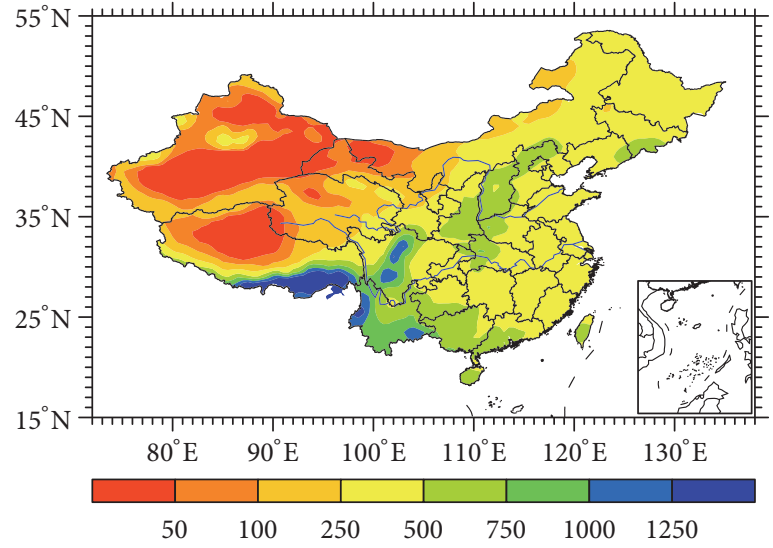

(a)

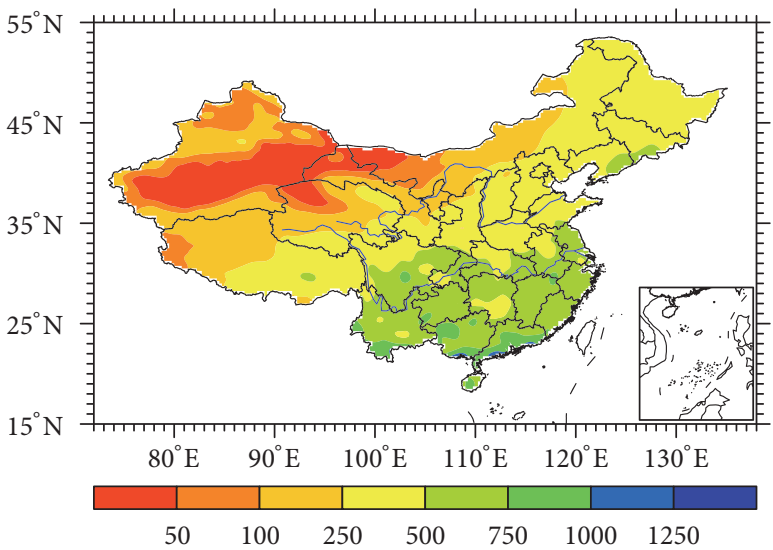

(c)

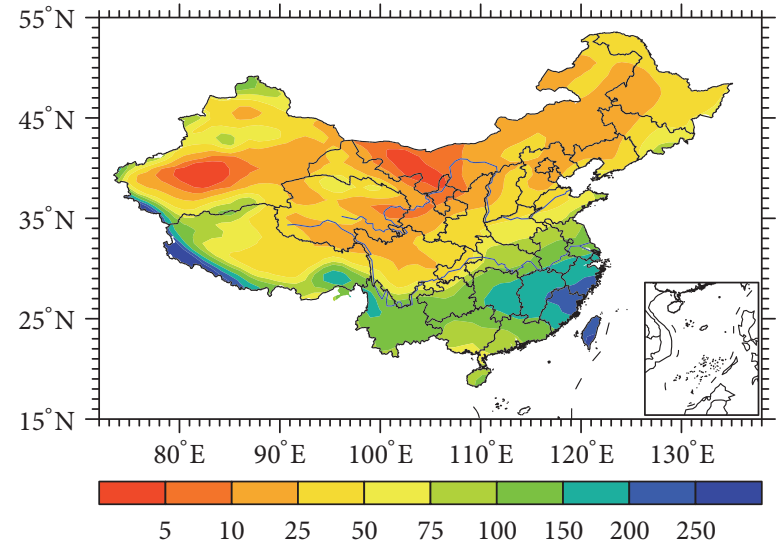

(b)

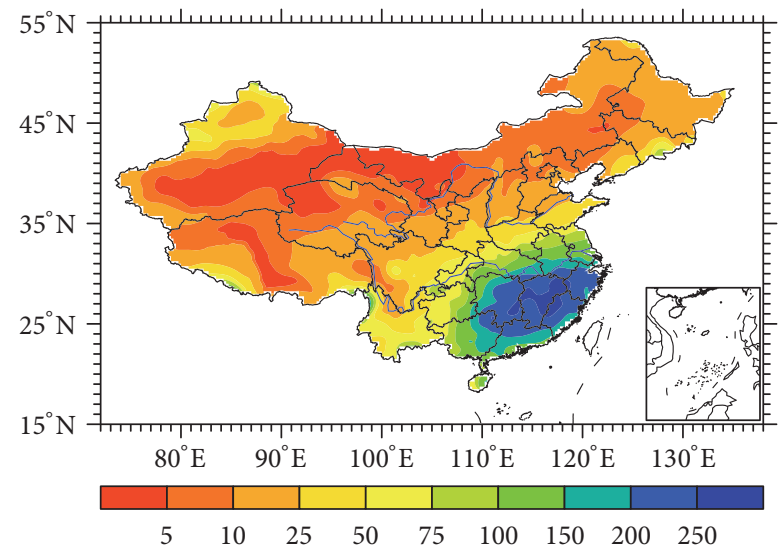

(d)

FIGURE 3: Mean precipitation over China (unit: mm). (a) Simulation in summer; (b) simulation in winter; (c) observations in summer; (d) observations in winter.

of wintertime precipitation is worse than the simulation of summertime precipitation in Northwest China and Northeast China.

Due to the large-scale precipitation scheme SUBEX can significantly improve the midlatitude rainfall simulation effect [28]; however, South China region is located in the low latitudes; this may be the reason why the simulated bias of precipitation in the region is greater than that in other regions. Because the representation of clouds and cloudrelated processes remains extremely problematic [9], the improvement of precipitation simulation is still one of the challenges of the regional climate model.

Compared with the previous studies of different versions of RegCM [23, 29-31], it is found that, for the simulation of winter precipitation center, RegCM4.5 is better than RegCM3. Compared with the RegCM4.4 using CLM3.5, the simulation deviation of the precipitation by the RegCM4.5 using CLM4.5 is obviously smaller, and the spatial correlation coefficient of the simulated and observed precipitation in summer and winter is greater. In addition, compared with RegCM4.3 using land surface scheme BATSle, RegCM4.5 partly overcomes the problem that the simulated value of winter precipitation in Southwest China is significantly larger than the observed value. In summary, compared to the previous version of RegCM, the ability to simulate precipitation with RegCM4.5 using CLM4.5 has been significantly improved.

Due to the modulation from monsoon, the rainband in East China exhibits clearly seasonal north-south migration. In order to examine whether the model is able to reproduce this feature, we plotted a time-latitude cross section map of monthly mean precipitation (Figure 4). According to observation data (Figure $4(\mathrm{~b})$ ), the rainband is south of $30^{\circ} \mathrm{N}$ before June. It gradually moves northward with enhanced precipitation, and two precipitation centers with the amount of precipitation over $250 \mathrm{~mm}$ appear in June. One of the centers is around $22^{\circ} \mathrm{N}$, where the strong rainfall was sustained until August, which reflects the impact from tropical synoptic systems such as typhoon and ITCZ over South China. The other center is around $29^{\circ} \mathrm{N}$, representing the Mei-Yu front along the Yangtze-Huai River. After September, the rainband retreats southward. In our experiments, the seasonal migration is successfully simulated as clearly depicted in Figure 4(a), with a correlation coefficient of 0.65 and RMSE of $54.1 \mathrm{~mm}$. However, Figure 4(c) also shows that the timing of migration as well as the magnitude of the precipitation is 


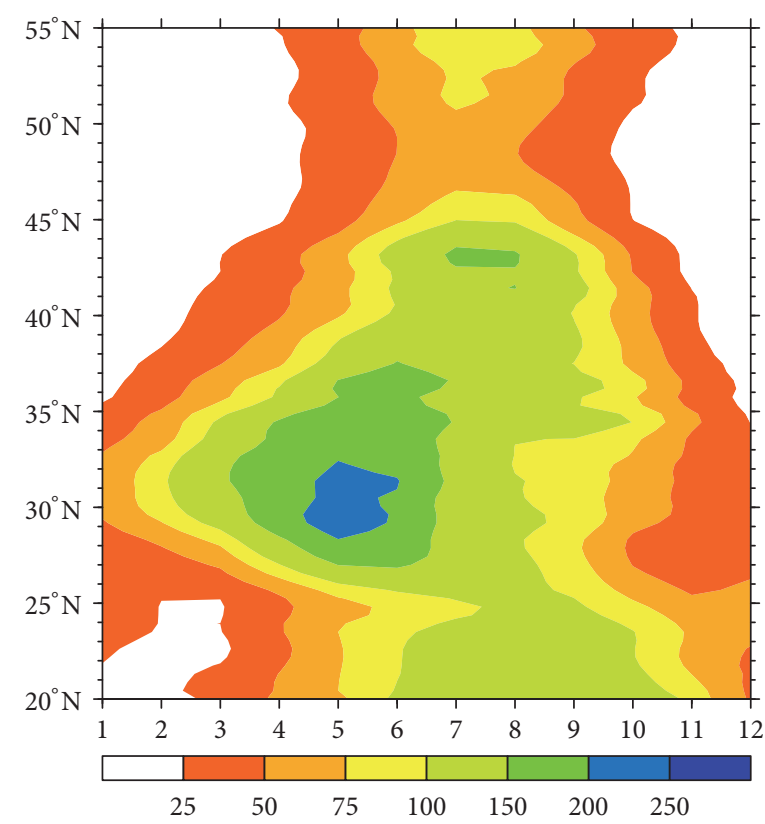

(a)

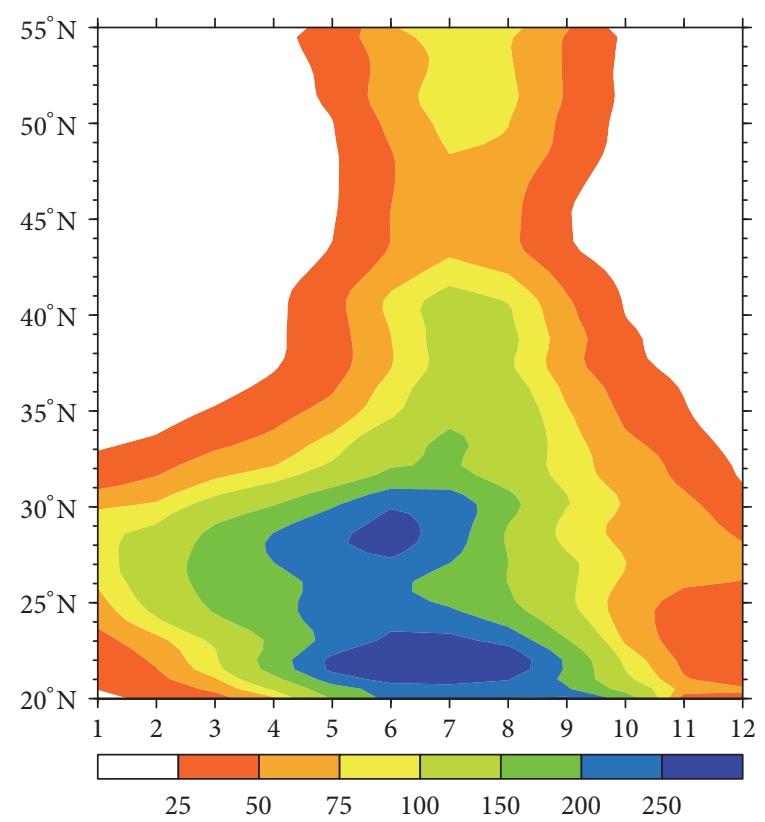

(b)

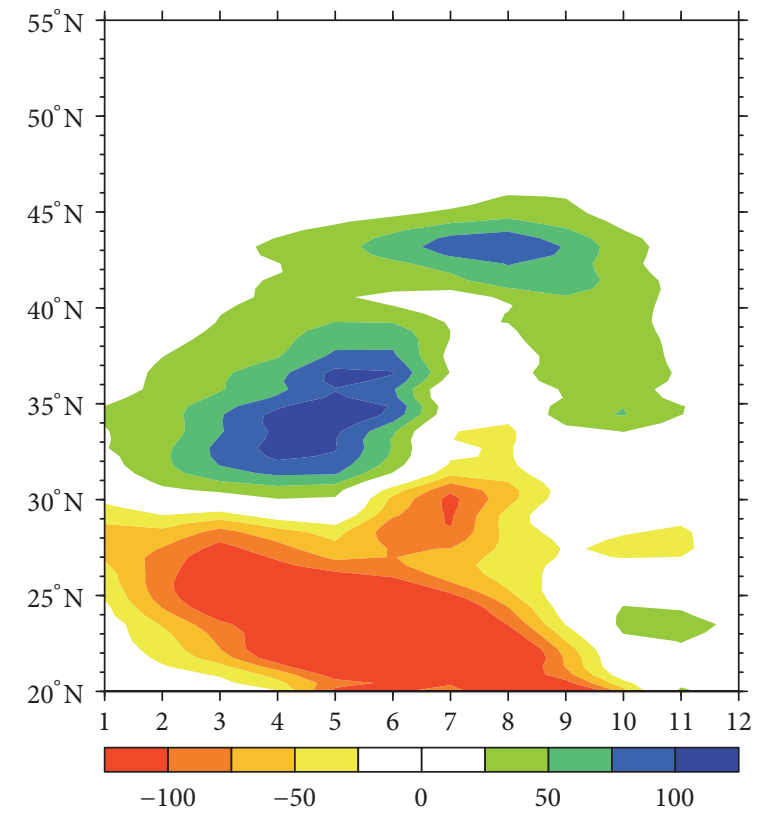

(c)

Figure 4: Time-Latitude map of mean monthly precipitation over East China ( $\left.110^{\circ} \mathrm{E}-120^{\circ} \mathrm{E}\right)$ (unit: $\mathrm{mm}$ ): (a) simulation, (b) observations, and (c) difference between simulation and observations.

not even close to the observations. The simulated rainband is generally 3 degrees north of the observations. The simulated rainbands over South China and Yangtze-Huai River appear one month earlier than the observed ones, though the simulation of rainband over North China is relatively better. The onset, maturation, and break time of Asia summer monsoon, to a large degree, determine the distribution of seasonal precipitation [32]. This implies that further improvement is needed for the model in simulating the East Asia monsoon. Overall, the model is skillful in simulating the pattern and seasonal migration of precipitation over China.
3.3. Soil Moisture. Wang [33] conducted offline simulation of soil moisture at $10 \mathrm{~cm}$ depth with CLM4.5. The results showed that the pattern of simulated $10 \mathrm{~cm}$ soil moisture is generally consistent with the observations. In this study, we followed their methods and carried out another offline simulation with CLM4.5 driven by atmospheric forcing data from Qian et al.s [34] dataset. The simulation period is 1952-2003, in which the period 1952-1983 served as spinup time. By comparing our RegCM4.5-CLM4.5 simulation with offline simulation, we can evaluate the capability of the coupled model in simulating soil moisture. Figure 5 shows 


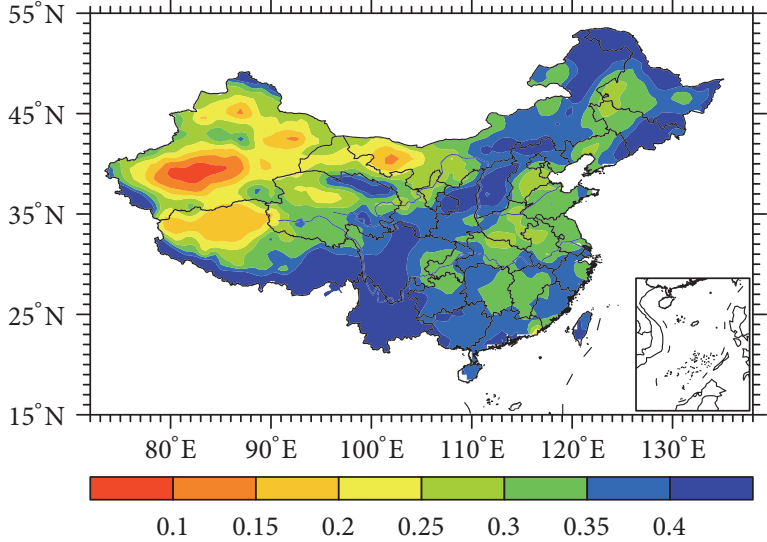

(a)

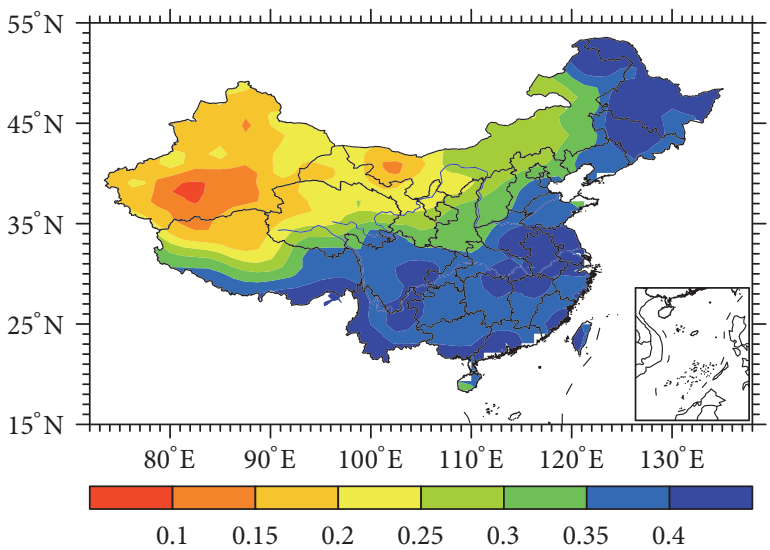

(c)

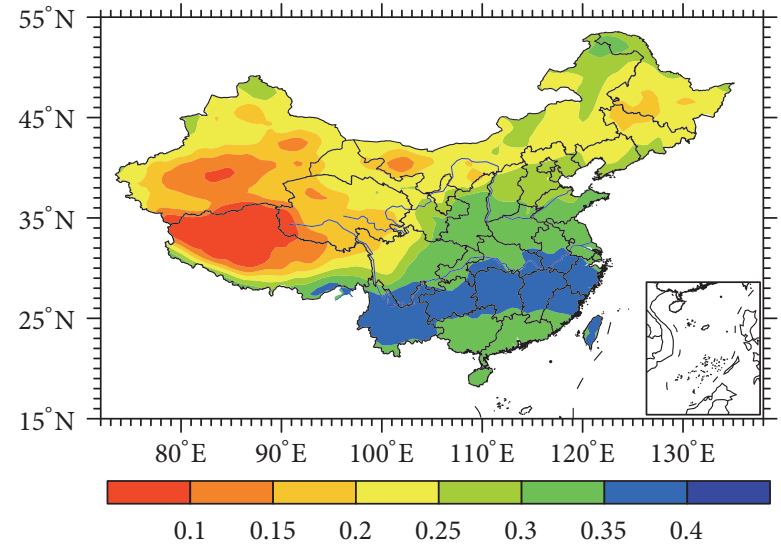

(b)

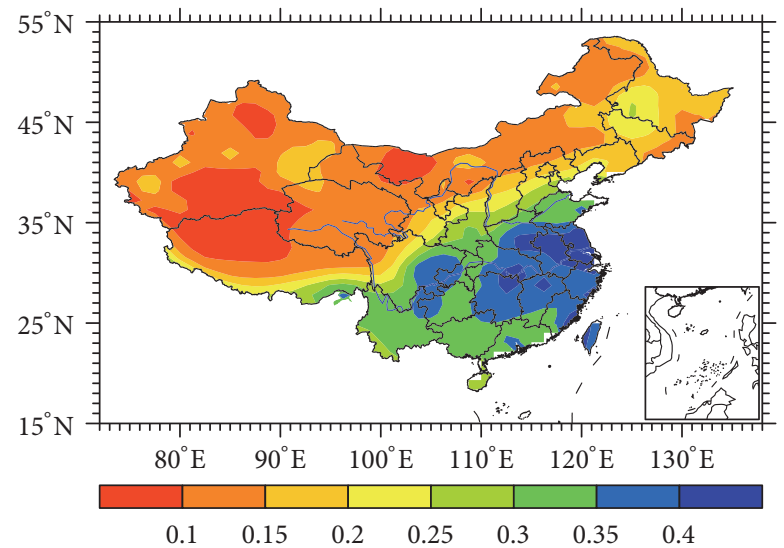

(d)

FIGURE 5: Mean soil water content at $10 \mathrm{~cm}$ subsurface over China. (a) and (b) are simulations for summer and winter; (c) and (d) are offline simulations for summer and winter.

the distribution of mean soil moisture (soil moisture content) at $10 \mathrm{~cm}$ depth in China during summer and winter. The coupled and offline simulations are shown in Figures 5(a), 5(b) and 5(c), 5(d) respectively. Figure 5(c) shows that the offline simulated summertime soil moisture content in China generally increases from northwest to northeast and southeast, which matches the well-known summertime "two-wet, one-dry" pattern of soil moisture distribution in China very well. However, the coupled simulation failed to reproduce this pattern (Figure 5(a)). Nevertheless, the area with soil moisture greater than 0.25 in couple simulation is consistent with the observations in spite of the accuracy of the centers of the maximum/minimum soil moisture and the magnitude as well as the wet bias in the north of the Yellow River. The correlations between the coupled and offline simulations are 0.64 and 0.72 for summer and winter, and the corresponding RMSE of coupled simulation is 0.11 and 0.08 , which indicates that the simulation for wintertime soil moisture is better than summer for the coupled model.

In the following paragraphs, the coupled simulation for each climatic zone will be analyzed. Table 3 lists the bias, RMSE, and correlation coefficients calculated based on coupled and offline simulations for each climate zone. It can be learned that the coupled model can simulate the spatial distribution of soil moisture very well in Northwest China and Plateau Zone. But it has nearly no skill in Northeast China, South China, and Southwest China during summer because, even for their very small correlation coefficients, the significance tests with significance level of 0.01 still failed. In Northeast China, the correlation coefficient is even negative. In contrast, the pattern of soil moisture during winter from coupled simulation is more consistent with the offline simulations compared with summer. Regarding bias, Wang [33] evaluated it with CLM series of models and pointed out that there is a positive bias for the simulated soil moisture. It should be mentioned that all these evaluations are based on offline simulations, and thus the land-atmosphere interaction was not considered. Zhang et al. [35] analyzed the simulated soil moisture in China from 14 global oceanland-atmosphere coupled models and suggested that the bias from coupled model simulation arises from the bias of the simulated precipitation. Based on numerical experiments, Meng and Zheng [36] also found that precipitation generated by the model has a crucial impact on soil moisture because it is calculated based on the simulated precipitation. Therefore, the negative bias of the simulated precipitation in East China 
TABLE 3: Bias, RMSE, and correlation coefficients of simulated soil moisture ( $*$ indicates not passing the significance test at a significance level of 0.01).

\begin{tabular}{|c|c|c|c|c|}
\hline & & Bias & RMSE & Correlation coefficient \\
\hline \multirow{7}{*}{ Summer } & North China & 0.01 & 0.09 & -0.60 \\
\hline & Northeast China & -0.02 & 0.09 & $-0.13^{*}$ \\
\hline & East China & -0.07 & 0.09 & -0.26 \\
\hline & South China & -0.05 & 0.06 & $0.10^{*}$ \\
\hline & Southwest China & 0.01 & 0.06 & $0.11^{*}$ \\
\hline & Northwest China & 0.06 & 0.09 & 0.53 \\
\hline & Plateau & 0.04 & 0.07 & 0.53 \\
\hline \multirow{7}{*}{ Winter } & North China & 0.03 & 0.06 & 0.59 \\
\hline & Northeast China & 0.05 & 0.08 & -0.49 \\
\hline & East China & -0.03 & 0.05 & 0.25 \\
\hline & South China & -0.03 & 0.05 & 0.36 \\
\hline & Southwest China & 0.01 & 0.04 & 0.86 \\
\hline & Northwest China & 0.09 & 0.09 & 0.61 \\
\hline & Plateau & 0.04 & 0.05 & 0.62 \\
\hline
\end{tabular}

TABLE 4: Correlation coefficients of monthly mean soil moisture from simulations and reanalysis during the period $1984-2003(*$ indicates not passing the significance test at a significance level of 0.01 ).

\begin{tabular}{cccccccc}
\hline & North China & Northeast China & East China & South China & Southwest China & Northwest China & Plateau \\
\hline Correlation coefficient & $-0.13^{*}$ & $-0.05^{*}$ & 0.33 & 0.65 & 0.34 & 0.68 & 0.29 \\
\hline
\end{tabular}

TABLE 5: Bias, RMSE, and correlation coefficients of simulated latent heat flux.

\begin{tabular}{lcccc}
\hline & & Rias $\left(\mathrm{kg} / \mathrm{m}^{2}\right)$ & RMSE $\left(\mathrm{kg} / \mathrm{m}^{2}\right)$ & Correlation coefficient \\
\hline \multirow{4}{*}{ Summer } & North China & 22.9 & 27.6 & 0.46 \\
& Northeast China & 3.5 & 13.2 & 0.69 \\
& East China & -12.1 & 23.7 & 0.36 \\
& South China & -25.6 & 35.5 & 0.86 \\
& Southwest China & -1.0 & 20.0 & 0.66 \\
& Northwest China & 18.9 & 24.8 & 0.75 \\
& Plateau & 0.1 & 14.7 & 0.65 \\
Winter & North China & 4.2 & 10.4 & 0.89 \\
& Northeast China & -2.9 & 10.0 & 0.86 \\
& East China & -1.3 & 26.1 & 0.82 \\
& South China & -2.0 & 7.2 & 0.93 \\
& Southwest China & -1.8 & 3.5 & 0.79 \\
Northwest China & 2.8 & 7.7 & 0.52 \\
\hline
\end{tabular}

and South China (Table 2) probably accounts for the negative bias of simulated soil moisture. In addition, strong coupling between land and atmosphere in Northwest China where it is arid and semiarid region [37] probably is responsible for the large bias of soil moisture in Northwest China. However, these results are also related to the selection of cumulus convection parameterization scheme and the feedback mechanism of soil moisture and precipitation $[17,38]$.

In order to examine how the model can simulate the temporal variation of soil moisture, we calculated the correlation between the time series of simulated monthly mean soil moisture and that from NASA reanalysis for the period 1984-2003 (Table 4). For North China and Northeast China, the corresponding correlations did not pass the significance test with the significance level of 0.01 . In contrast, the correlation coefficients for South China and Northwest China are as large as 0.65 and 0.68 . This indicates that the model has no skill in simulating temporal variation of monthly mean soil moisture in North China and Northeast China, but it is very skillful in South China and Northwest China.

3.4. Latent Heat Flux. Figure 6 shows mean latent heat flux over China during summer and winter from simulation and reanalysis while Table 5 shows the bias, RMSE, and correlation coefficients in each zone. The correlation between the simulation and reanalysis is 0.82 and 0.96 for summer 


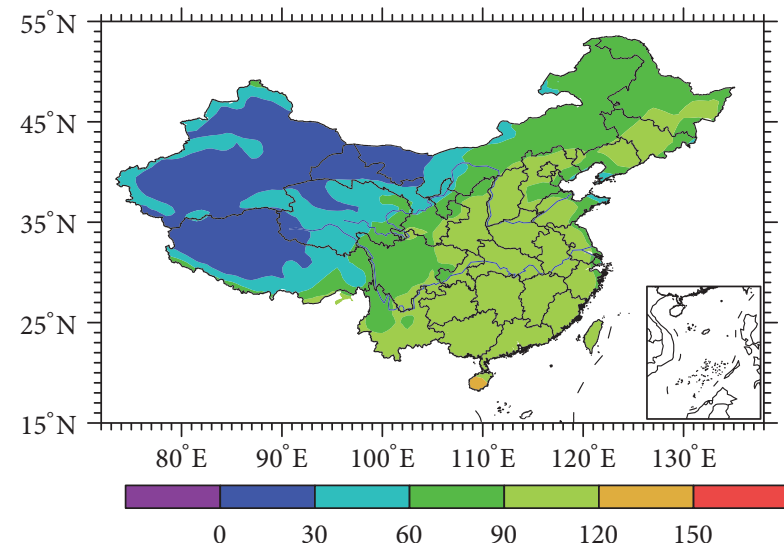

(a)

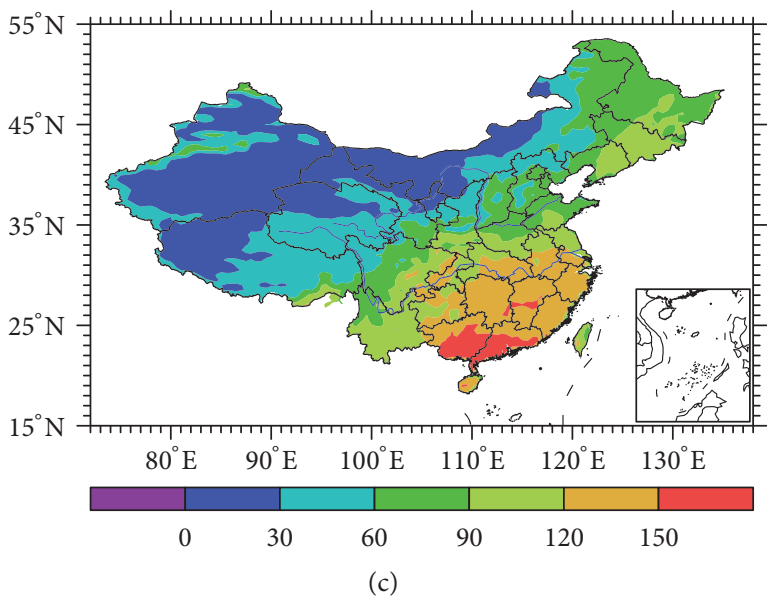

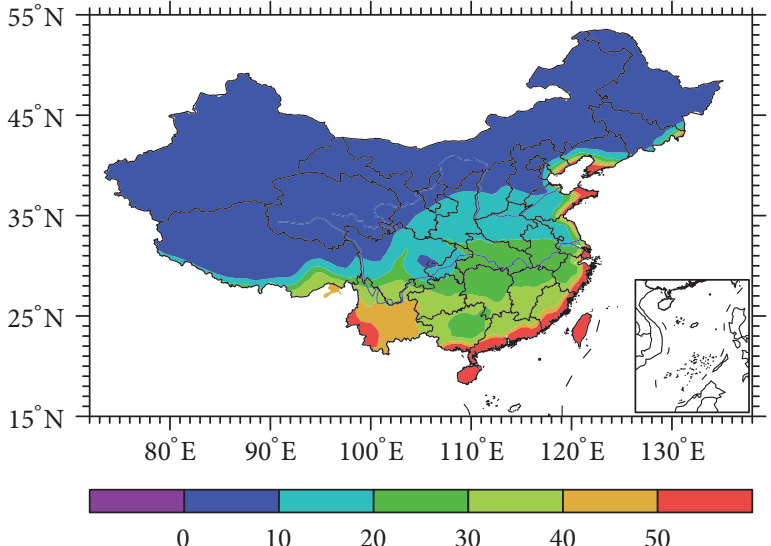

(b)

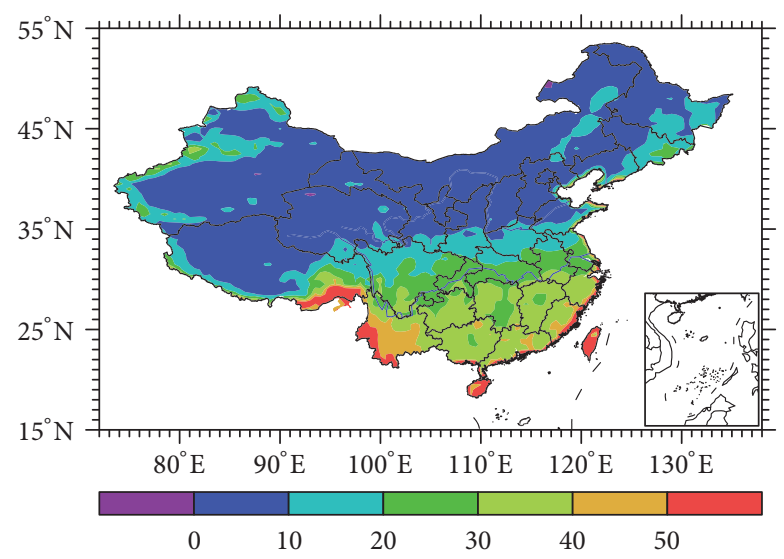

(d)

FIgURE 6: Same as Figure 3 but for latent heat flux (unit: $\mathrm{W} / \mathrm{m}^{2}$ ).

and winter, and the corresponding RMSE is $23.0 \mathrm{~W} / \mathrm{m}^{2}$ and $26.4 \mathrm{~W} / \mathrm{m}^{2}$, respectively. According to Figures 6(a) and 6(c), the model failed to simulate the area with large latent heat flux greater than $150 \mathrm{~W} / \mathrm{m}^{2}$ in Guangdong and Guangxi provinces, which results in the largest bias and RMSE in South China during summer. However, the overall simulated pattern is still reasonably well in South China. There is a large positive bias in North China and Northwest China for the simulation of summertime latent heat flux distribution. In East China, though the correlation between the simulated and observed latent heat flux passed the significance test with the significance level of 0.01 , its value is only 0.36 . There is also a negative bias of $-12.1 \mathrm{~W} / \mathrm{m}^{2}$ with RMSE of $23.7 \mathrm{~W} / \mathrm{m}^{2}$ during summer in East China. This reflects that the model has lower capability in simulating the summertime latent heat flux in East China. In the meantime, in terms of model bias and simulated spatial distribution patterns, the wintertime simulation is generally better for all the climatic zones.

It is interesting to note that the model performs very well in simulating the spatial distribution of latent heat flux in South China during both summer and winter with the correlation coefficients of 0.86 and 0.93 , respectively, but the corresponding RMSEs are also very high, with the value of $35.5 \mathrm{~W} / \mathrm{m}^{2}$ and $26.1 \mathrm{~W} / \mathrm{m}^{2}$ for winter and summer.
In addition, the model bias is also large in summer, with a negative value of $-25.6 \mathrm{~W} / \mathrm{m}^{2}$. This reveals that spatial distribution of latent heat flux in South China is probably well simulated, but with systematic bias, especially that there is a large negative bias in summer. In spite of this, compared to the RegCM4.3 using land surface scheme BATS [39], which has obviously larger simulation deviation of latent heat flux in Northeast China and Southwest China in summer and Southern China in winter, the simulation bias is significantly smaller with RegCM4.5 using CLM4.5. This shows that the ability of RegCM4.5 to simulate the latent heat flux in some areas has been improved partly.

As latent heat flux comes from surface evaporation and evapotranspiration, in order to trace the source of the model bias in latent heat flux over China, especially over South China, we analyzed surface evaporation. Figure 7 shows simulated and observed surface evaporation during summer and winter over China. The correlation coefficient and RMSE are 0.55 and $16.1 \mathrm{~W} / \mathrm{m}^{2}$ for summer and 0.66 and $6.3 \mathrm{~W} / \mathrm{m}^{2}$ for winter. Table 6 lists the bias, RMSE, and correlation coefficients of surface evaporation at each climatic zone. It can be seen that the RMSE and bias are very large in Southwest China and Plateau Zone during summer, and the correlation coefficient is -0.04 and 0.22 , respectively, indicating that 
TABLE 6: Bias, RMSE, and correlation coefficients of simulated surface evaporation $(*$ indicates not passing the significance test at a significance level of 0.01).

\begin{tabular}{ccccc}
\hline & & Rias $\left(\mathrm{W} / \mathrm{m}^{2}\right)$ & Correlation coefficient \\
\hline \multirow{4}{*}{ Summer $\left(\mathrm{W} / \mathrm{m}^{2}\right)$} & 22.9 & 0.29 \\
& North China & 19.9 & 9.3 & 0.58 \\
& Northeast China & 5.8 & 8.7 & 0.59 \\
& East China & -2.5 & 12.1 & 0.41 \\
& South China & -3.2 & 18.1 & $-0.04^{*}$ \\
& Southwest China & -7.6 & 17.6 & 0.65 \\
& Northwest China & 13.3 & 14.7 & 0.22 \\
\hline \multirow{4}{*}{ Winter } & Plateau & -13.5 & 6.5 & 0.82 \\
& North China & 6.0 & 3.7 & 0.56 \\
& Northeast China & 3.4 & 5.4 & 0.74 \\
East China & 0.9 & 5.5 & 0.33 \\
& South China & -5.3 & 7.2 & 0.67 \\
& Southwest China & 3.3 & 4.3 & 0.48 \\
Northwest China & 4.1 & 6.2 & 0.64 \\
\hline
\end{tabular}

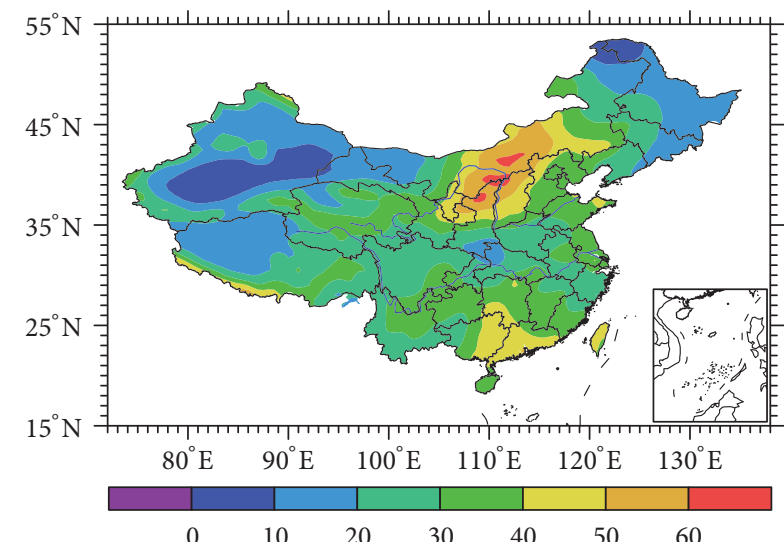

(a)

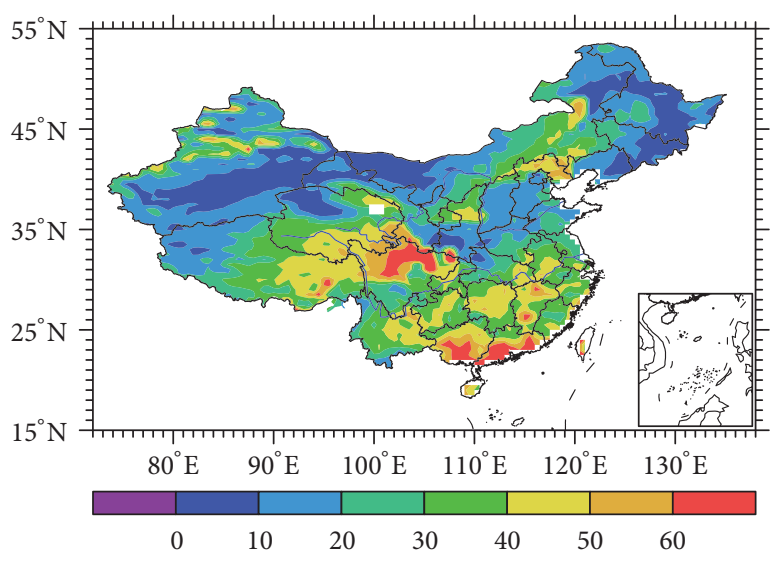

(c)

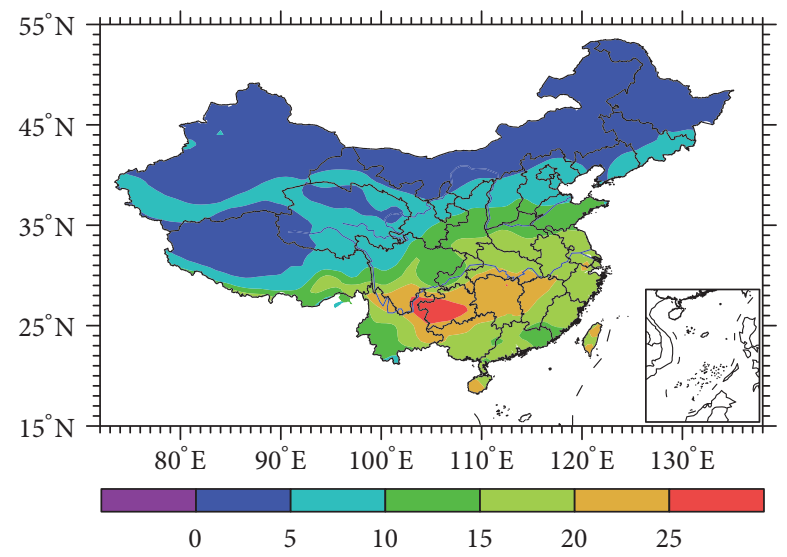

(b)

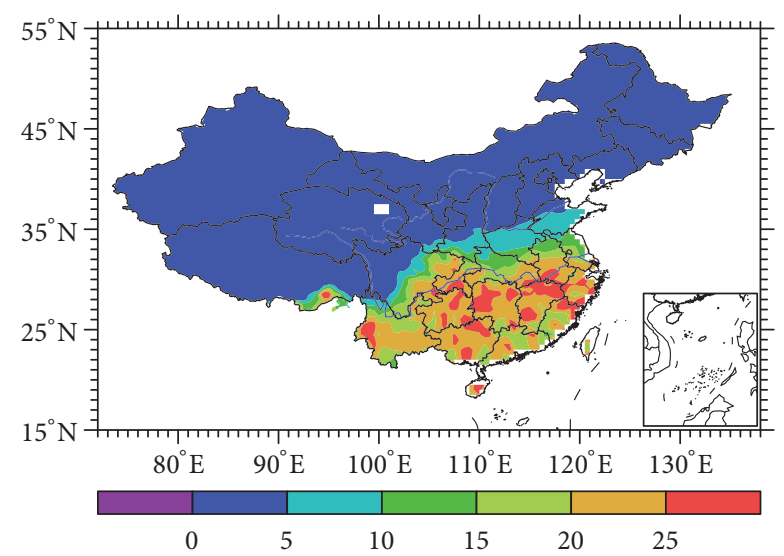

(d)

Figure 7: Same as Figure 3 but for surface evaporation (unit: W/m²).

the model cannot successfully simulate surface evaporation during summer in these two climatic zones. For wintertime simulation, the correlation coefficients for South China and Northwest China are small, which means the model has lower capability in simulating the pattern of surface evaporation there. As the model has negative precipitation bias over South China, it results in less soil moisture and thus less surface evaporation. The surface evaporation bias in South China is $-3.2 \mathrm{~W} / \mathrm{m}^{2}$ which is only $12.5 \%$ of the latent heat flux bias there. However, the surface evaporation bias is $86.9 \%$ of the 
TABLE 7: Bias, RMSE, and correlation coefficients of evapotranspiration (* indicates not passing the significance test at a significance level of $0.01)$.

\begin{tabular}{|c|c|c|c|c|}
\hline & & $\operatorname{Bias}\left(\mathrm{W} / \mathrm{m}^{2}\right)$ & $\operatorname{RMSE}\left(\mathrm{W} / \mathrm{m}^{2}\right)$ & Correlation coefficient \\
\hline \multirow{7}{*}{ Summer } & North China & 3.0 & 14.4 & 0.50 \\
\hline & Northeast China & -2.3 & 15.3 & 0.64 \\
\hline & East China & -9.6 & 20.2 & $0.10^{*}$ \\
\hline & South China & -22.4 & 37.1 & $0.12^{*}$ \\
\hline & Southwest China & 6.6 & 29.8 & 0.48 \\
\hline & Northwest China & 5.6 & 10.0 & 0.47 \\
\hline & Plateau & 13.6 & 20.9 & 0.25 \\
\hline \multirow{7}{*}{ Winter } & North China & -1.8 & 8.7 & 0.44 \\
\hline & Northeast China & -6.3 & 11.4 & 0.32 \\
\hline & East China & -2.2 & 5.1 & 0.51 \\
\hline & South China & 3.3 & 20.1 & $0.12^{*}$ \\
\hline & Southwest China & -5.1 & 7.6 & 0.54 \\
\hline & Northwest China & -1.3 & 2.6 & $0.10^{*}$ \\
\hline & Plateau & -10.3 & 12.9 & 0.37 \\
\hline
\end{tabular}

latent heat flux bias in North China, which indicates that the surface evaporation bias is the major contributor for the bias of the latent heat flux there.

As evapotranspiration is one of the key factors that has a major impact on the hydrological cycle and the evapotranspiration from canopy interception is nearly $10-30 \%$ of total precipitation $[40,41]$, it is reasonable to consider the effect of evapotranspiration on latent heat flux bias. Though it is difficult to obtain observations of evapotranspiration, an acceptable alternate way is to use the difference between latent heat flux and surface evaporation as a proxy of evapotranspiration. By doing this, we obtained correlation coefficient and RMSE of evapotranspiration which are 0.80 and $19.6 \mathrm{~W} / \mathrm{m}^{2}$ for summer and 0.49 and $18.3 \mathrm{~W} / \mathrm{m}^{2}$ for winter. Table 7 lists the bias, RMSE, and correlation coefficients for each climatic zone during summer and winter. It is clear that the simulation of evapotranspiration in South China is not successful. The correlation coefficients for summer and winter are both only 0.12 , and they are also not statistically significant given the significance level of 0.01 . On the other hand, less precipitation and drier soil limit the canopy interception and evapotranspiration, which results in large RMSE in this zone than that in other zones. The RMSE is $37.1 \mathrm{~W} / \mathrm{m}^{2}$ in summer and $20.1 \mathrm{~W} / \mathrm{m}^{2}$ for winter. The evapotranspiration bias is $87.5 \%$ of latent heat flux bias, which supports our previous speculation that the latent heat flux bias is primarily attributable to the evapotranspiration bias, which is not the case for other zones.

In order to further analyze the possible reason for the cause of the evapotranspiration bias, Figure 8 shows distribution of 17 PFT (Plant Functional Types) from MODIS (Moderate Resolution Imaging Spectroradiometer) vegetation data which is the default option for vegetation cover used in RegCM4.5. Compared with the high-resolution map of vegetation distribution in China (http://www.nsii.org .cn/mapvege), it is clear that, even for a sophisticated land surface model like CLM4.5, the vegetation is still treated very roughly with substantial discrepancies. The mild climate and abundant precipitation determine that the dominant

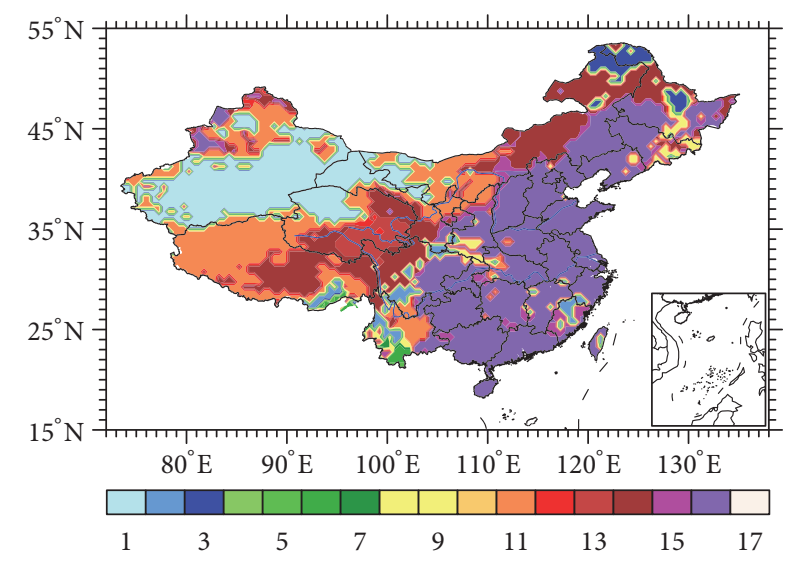

FIGURE 8: Distribution of PFT over China from MODIS vegetation cover (default option in RegCM4.5 model) (1: no vegetation; 2 : temperate needleleaf evergreen tree; 3 : boreal needleleaf evergreen tree; 4: boreal needleleaf deciduous tree; 5: tropical broadleaf evergreen tree; 6: temperate broadleaf evergreen tree; 7 : tropical broadleaf deciduous tree; 8: temperate broadleaf deciduous tree; 9: boreal broadleaf deciduous tree; 10: temperate broadleaf evergreen shrub; 11: temperate broadleaf deciduous shrub; 12: boreal broadleaf deciduous shrub; 13: arctic grass; 14: $\mathrm{C}_{3}$ grass; $15: \mathrm{C}_{4}$ grass; $16: \mathrm{C}_{3}$ rainfed crop; 17: $\mathrm{C}_{3}$ irritated crop).

vegetation type in South China is broadleaf evergreen tree, and it is rainforest type for the coastal region in Guangdong and Guangxi provinces. These vegetation types have a larger canopy structure which makes it easy to intercept more precipitation and later give back to the atmosphere through evapotranspiration. And the special stomatal structure of this type of vegetation also facilitates more active evapotranspiration and more soil moisture can be absorbed by the root and then released back to the atmosphere thorough stoma. Some studies have already demonstrated that variation of vegetation can have a profound impact on the exchange of energy between land and atmosphere. Therefore, the 
failing of representation of the vegetation distribution in South China and negative model bias for precipitation led to the negative bias for simulations of evapotranspiration and surface evaporation, which is possibly the reason for the large bias for simulation of latent heat flux in South China during summer.

\section{Conclusions}

A 40-year simulation of land surface climate over China is conducted using RegCM4.5 coupled with CLM4.5. The initial and lateral boundary conditions are provided by the NCEP-NCAR reanalysis. By analyzing the simulated land surface temperature, precipitation, soil moisture, latent heat flux, and surface evaporation and comparing them with observations, we learned the capability of the coupled model in simulating the land surface processes in various climatic zones in China. It is found that the ability of RegCM4.5 to simulate precipitation and latent heat flux is significantly stronger than that of previous versions of RegCM. Some of the major conclusions are as follows:

(1) The coupled model is very skillful in simulating land surface temperature over China. Several seasonal features (e.g., surface temperature above $15^{\circ} \mathrm{C}$ for most regions in summer, large temperature gradient over the land in winter, and land surface temperature contour tending to parallel latitude) are reproduced very well. Furthermore, the model can simulate spatial distribution of land surface temperature as well as the location of the maximum and minimum temperature very well.

(2) The model has better capability in simulating the amount of precipitation and spatial pattern in Northeast China and Northwest China during summer than in other regions. However, large negative precipitation bias also exists for the simulation in the southeast monsoon regions and South China. The model can simulate the center of precipitation during winter very well, but the spatial distribution overall is not as good as that in summer. The seasonal migration of rainband in East China can also be simulated reasonably, except for the large discrepancy in timing of the rainband migration and spatial distribution.

(3) Land-atmosphere interaction has a profound influence on the model in simulating soil moisture. In summer, the model is unable to simulate a coherent spatial distribution of soil moisture in Northeast, South, and Southwest China. However, it can overall reasonably reproduce the spatial distribution of soil moisture in winter. The simulated soil moisture in each zone is also better in winter than in summer. For simulation of monthly variation, the model is not good in North and Northeast China, but much better in South and Northwest China.

(4) Compared with the simulation of summertime latent heat flux, it is much better for the simulation of wintertime latent heat flux. The latent heat flux bias in North China during summer is primarily caused by the precipitation bias as well as the insufficient representation of vegetation cover in that region.

Through the verification of the simulation ability of RegCM4.5 coupled with CLM4.5 and the analysis of the possible causes of error, the potential application of this work, to a certain extent, is to promote the application of this model to real businesses in China. In addition, it is necessary to point out that canopy interception is one of the important components in the hydrological cycle, and also it is recognized as a crucial hydrological process under a changing climate. The percentage of canopy interception is about $25 \%$ of annual precipitation in rainforest region [42]. Yin and Chen [43] calculated RMSE of evapotranspiration from canopy interception for 13 vegetation types using CLM model and found that the simulation error for tropical and temperate evergreen broadleaf trees is larger than that of other types of vegetation. This implies that even if we use the high-quality vegetation data, it is possible that we still cannot obtain satisfying results due to the defect of the model parameterization itself.

\section{Conflicts of Interest}

The authors declare no conflicts of interest.

\section{Acknowledgments}

This work was supported financially by the National Natural Science Foundation of China (Grant no. 41475071).

\section{References}

[1] F. Giorgi, "Simulation of regional climate using a limited area model nested in a general circulation model," Journal of Climate, vol. 3, no. 9, pp. 941-963, 1990.

[2] G. Xuejie, Z. Zongci, D. Yihui, H. Ronghui, and F. Giorgi, "Climate change due to greenhouse effects in China as simulated by a regional climate model," Advances in Atmospheric Sciences, vol. 18, no. 6, pp. 1224-1230, 2001.

[3] N. Salzmann and L. O. Mearns, "Assessing the performance of multiple regional climate model simulations for seasonal mountain snow in the Upper Colorado River Basin," Journal of Hydrometeorology, vol. 13, no. 2, pp. 539-556, 2012.

[4] K. W. Oleson, G. B. Lawrence, B. Drewniak et al., "Technical Description of version 4.5 of the Community Land Model (CLM)," NCAR Technical Note NCAR/TN+STR, Natl. Cent. for Atmos. Res., Boulder, Colo. pp. 434, 2013.

[5] R. E. Dickinson, "Land Surface Processes and Climate-Surface Albedos and Energy Balance," Advances in Geophysics, vol. 25, no. C, pp. 305-353, 1983.

[6] R. E. Dickinson, "Land processes in climate models," Remote Sensing of Environment, vol. 51, no. 1, pp. 27-38, 1995.

[7] M. Widmann and C. S. Bretherton, "Statistical precipitation downscaling over the northwestern united states using numerically simulated precipitation as a predictor," Journal of Climate, vol. 16, no. 5, pp. 799-816, 2003.

[8] B. J. J. M. van den Hurk and E. van Meijgaard, "Diagnosing land-atmosphere interaction from a regional climate model simulation over West Africa," Journal of Hydrometeorology, vol. 11, no. 2, pp. 467-481, 2010. 
[9] R. L. Gianotti and E. A. B. Eltahir, "Regional climate modeling over the maritime continent. Part I: New parameterization for convective cloud fraction," Journal of Climate, vol. 27, no. 4, pp. 1488-1503, 2014.

[10] M. Notaro, A. Zarrin, S. Vavrus, and V. Bennington, "Simulation of heavy lake-effect snowstorms across the great lakes basin by RegCM4: Synoptic climatology and variability,' Monthly Weather Review, vol. 141, no. 6, pp. 1990-2014, 2013.

[11] L. Zou, Y. Qian, T. Zhou, and B. Yang, "Parameter tuning and calibration of RegCM3 with MIT-emanuel cumulus parameterization scheme over CORDEX East Asia domain," Journal of Climate, vol. 27, no. 20, pp. 7687-7701, 2014.

[12] Z. Wang and C.-P. Chang, "A numerical study of the interaction between the large-scale monsoon circulation and orographic precipitation over South and Southeast Asia," Journal of Climate, vol. 25, no. 7, pp. 2440-2455, 2012.

[13] M. P. Marcella and E. A. B. Eltahir, "Modeling the summertime climate of Southwest Asia: the role of land surface processes in shaping the climate of semiarid regions," Journal of Climate, vol. 25, no. 2, pp. 704-719, 2012.

[14] D. Zhang and Y. Shi, "Numerical simulation of climate changes over North China by the model RegCM3," Chinese Journal of Geophysics, vol. 55, no. 5, pp. 474-487, 2012.

[15] X. Gao, Y. Shi, Z. Han et al., "Performance of RegCM4 over major river basins in China," Advances in Atmospheric Sciences, vol. 34, no. 4, pp. 441-455, 2017.

[16] M. G. Bosilovich and W. Y. Sun, "Numerical simulation of the 1993 Midwestern flood: Landatmosphere interactions," Journal of Climate, vol. 12, no. 5, pp. 1490-1505, 1999.

[17] J. S. Pal and E. A. B. Eltahir, "Pathways relating soil moisture conditions to future summer rainfall within a model of the landatmosphere system," Journal of Climate, vol. 14, no. 6, pp. 12271242, 2001.

[18] Y. Wang, O. L. Sen, and B. Wang, "A highly resolved regional climate model (IPRC-RegCM) and its simulation of the 1998 severe precipitation event over China. Part I. Model description and verification of simulation," Journal of Climate, vol. 16, no. 11, pp. 1721-1738, 2003.

[19] J. Zou and Z. Xie, "The effects of the Land-surface process parameterization of the RegCM4 on climate simulation in East Asia," Acta Meteorologica Sinica, vol. 70, no. 6, pp. 1312-1326, 2012 (Chinese).

[20] X. Wang, M. Yang, and G. Pang, "Influences of two land-surface schemes on regcm 4 precipitation simulations over the tibetan plateau," Advances in Meteorology, vol. 2015, Article ID 106891, 12 pages, 2015.

[21] Y. Ding, Q. Li, and W. Dong, "A Numerical Simulation Study of the Impacts of Vegetation Changes on Regional Climate in China," Acta Meteorologica Sinica, vol. 63, no. 5, pp. 613-621, 2005 (Chinese).

[22] X. Fang, S. Luo, S. Lyu et al., "A Simulation and Validation of CLM during Freeze-Thaw on the Tibetan Plateau," Advances in Meteorology, vol. 2016, Article ID 9476098, 15 pages, 2016.

[23] X.-J. Gao, Y. Shi, and F. Giorgi, "Comparison of convective parameterizations in RegCM4 experiments over China with CLM as the land surface model," Atmospheric and Oceanic Science Letters, vol. 9, no. 4, pp. 246-254, 2016.

[24] Y. Ma, X.-M. Zeng, Y. Zhang et al., "Impact of the Choice of Land Surface Scheme on a Simulated Heatwave Event: The Case of Sichuan-Chongqing Area, China," Advances in Meteorology, vol. 2017, Article ID 9545896, 2017.
[25] E. O. Gbobaniyi, B. J. Abiodun, M. A. Tadross, B. C. Hewitson, and W. J. Gutowski, "The coupling of cloud base height and surface fluxes: A transferability intercomparison," Theoretical and Applied Climatology, vol. 106, no. 1-2, pp. 189-210, 2011.

[26] J. Wu and X.-J. Gao, "A gridded daily observation dataset over China region and comparison with the other datasets," Chinese Journal of Geophysics, vol. 56, no. 4, pp. 1102-1111, 2013 (Chinese).

[27] Q. Li and Y. Ding, "Multi-year simulation of the East Asian Monsoon and precipitation in China using a regional climate model and evaluation," Acta Meteorologica Sinica, vol. 19, no. 3, pp. 140-153, 2004 (Chinese).

[28] J. S. Pal, E. E. Small, and E. A. B. Eltahir, "Simulation of regionalscale water and energy budgets: representation of subgrid cloud and precipitation processes within RegCM," Journal of Geophysical Research: Atmospheres, vol. 105, no. D24, pp. 2957929594, 2000.

[29] D. Zhang, X. Gao, L. Ouyang, and W. Dong, "Simulation of Present Climate over East Asia by regional climate model," Journal of Meteorological Research, vol. 14, no. 1, pp. 19-24, 2008.

[30] X. J. Gao, Y. Shi, and F. Giorgi, "A high resolution simulation of climate change over China," Science China Earth Sciences, vol. 54, no. 3, pp. 462-472, 2011.

[31] S. Zhang, S. Lü, Y. Bao, and D. Ma, "Sensitivity of precipitation over China to different cumulus parameterization schemes in RegCM4," Journal of Meteorological Research, vol. 29, no. 1, pp. 119-131, 2015.

[32] M. Stowasser, H. Annamalai, and J. Hafner, "Response of the South Asian summer monsoon to global warming: Mean and synoptic systems," Journal of Climate, vol. 22, no. 4, pp. 10141036, 2009.

[33] D. Wang, Study on Soil Moisture Simulated by CLM4.5 and Its Spatial and Temporal Variation in China, Nanjing university of information science and technology, Nanjing, China, 2015.

[34] T. T. Qian, A. G. Dai, K. E. Trenberth, and K. W. Oleson, "Simulation of global land surface conditions from 1948 to 2004. Part I: forcing data and evaluations," Journal of Hydrometeorology, vol. 7, no. 5, pp. 953-975, 2006.

[35] W. Zhang, R. Yu, and T. Zhou, "Spatial distribution and temporal variation of soil moisture over china. part ii: the evaluations for coupled models' simulations," Chinese Journal of Atmospheric Science, vol. 32, no. 5, pp. 1128-1146, 2008 (Chinese).

[36] W. Meng and B. Zheng, "The features of South China sea summer monsoon onset of 2004 and the possible effects of land-surface process in indo-china peninsula ii: numerical simulation," Acta Meteorologica Sinica, vol. 64, no. 1, pp. 81-89, 2006.

[37] P. A. Dirmeyer, Y. Jin, C. Csingh, and C. Yan, "Evolving landatmosphere interactions over North America from CMIP5 simulations," Journal of Climate, vol. 26, no. 19, pp. 7313-7327, 2013.

[38] Y. Kim and G. Wang, "Impact of initial soil moisture anomalies on subsequent precipitation over North America in the coupled land-atmosphere model CAM3-CLM3," Journal of Hydrometeorology, vol. 8, no. 3, pp. 513-533, 2007.

[39] S. Ali, L. Dan, C. Fu, and Y. Yang, "Performance of convective parameterization schemes in Asia using RegCM: Simulations in three typical regions for the period 1998-2002," Advances in Atmospheric Sciences, vol. 32, no. 5, pp. 715-730, 2015.

[40] P. J. Zinke, "Forest interception studies in the United States," in International symposium on Forest Hydrology, pp. 137-161, Pergamon Press, Oxford, UK, 1967. 
[41] G. J. Blake, “The Interception Process," in Prediction in Catchment Hydrology, T. G. Dunin, Ed., pp. 59-81, Australian Academy of Science, Canberra, Australia, 1975.

[42] S. Dingman, Physical Hydrology, Prentice Hall, Upper Saddle River, NJ, USA, 2002.

[43] Y. Yin and H. Chen, "Numerical experiment of impacts of canopy interception on land surface water and energy balance," Journal of the Meteorological Sciences, vol. 33, no. 2, pp. 119-129, 2013 (Chinese). 

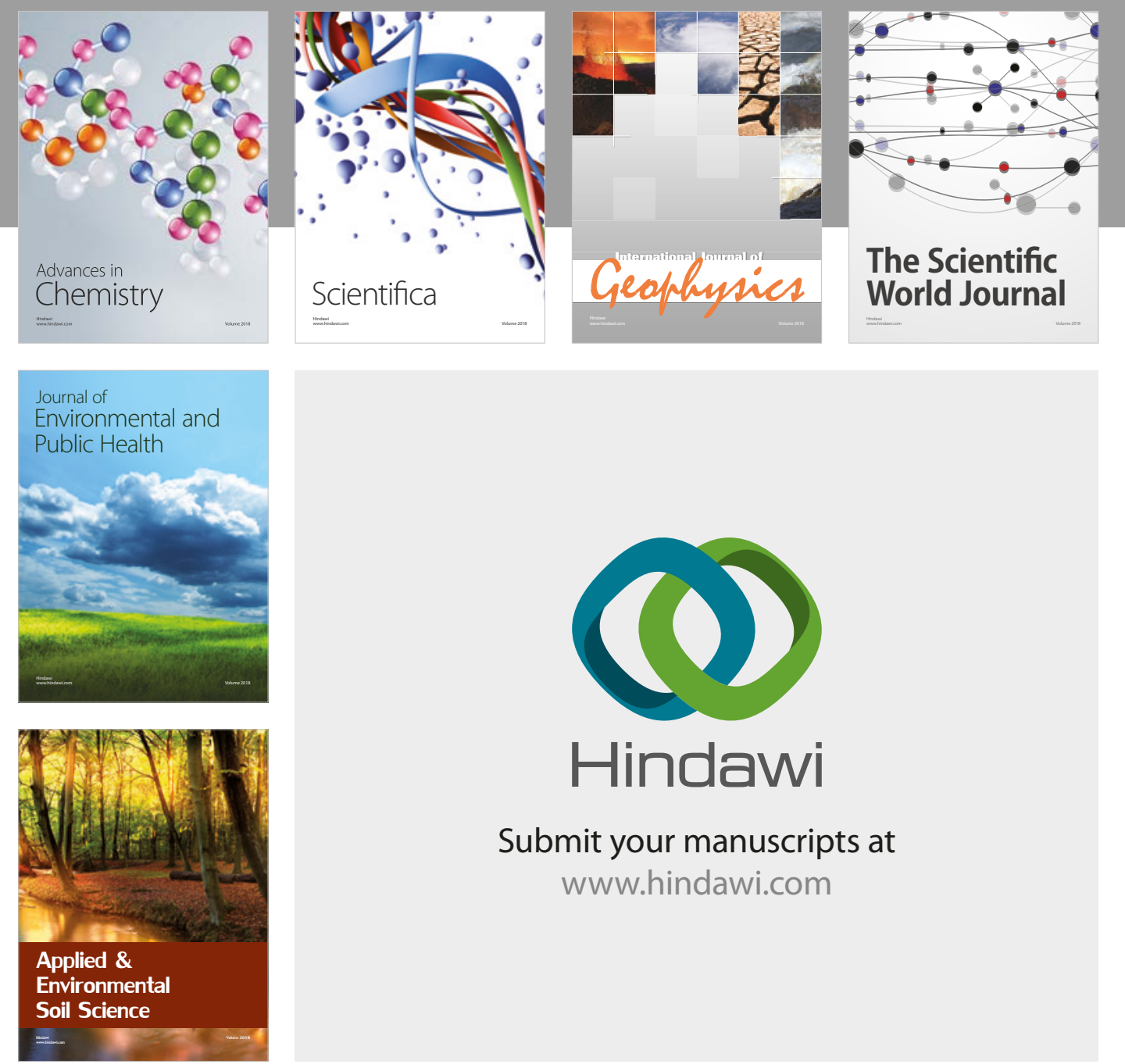

The Scientific

\section{World Journal}
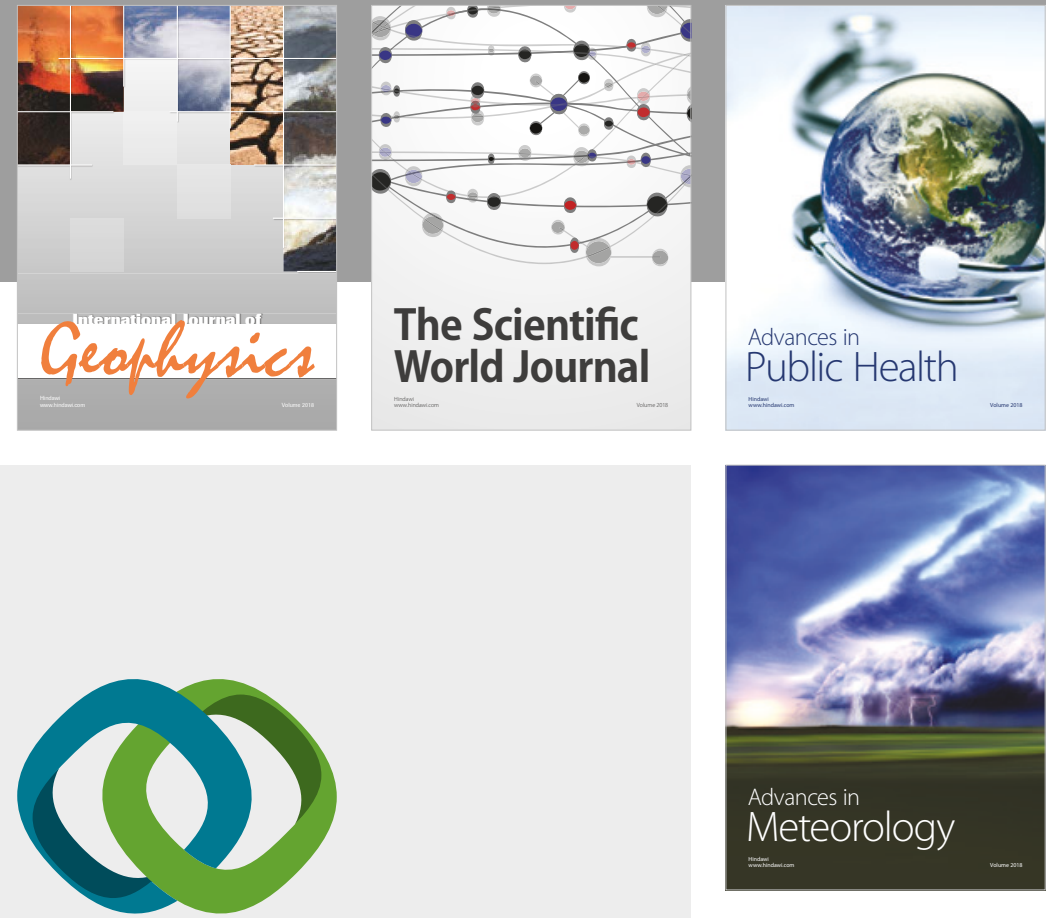

Advan

Public Health

\section{Hindawi}

Submit your manuscripts at

www.hindawi.com
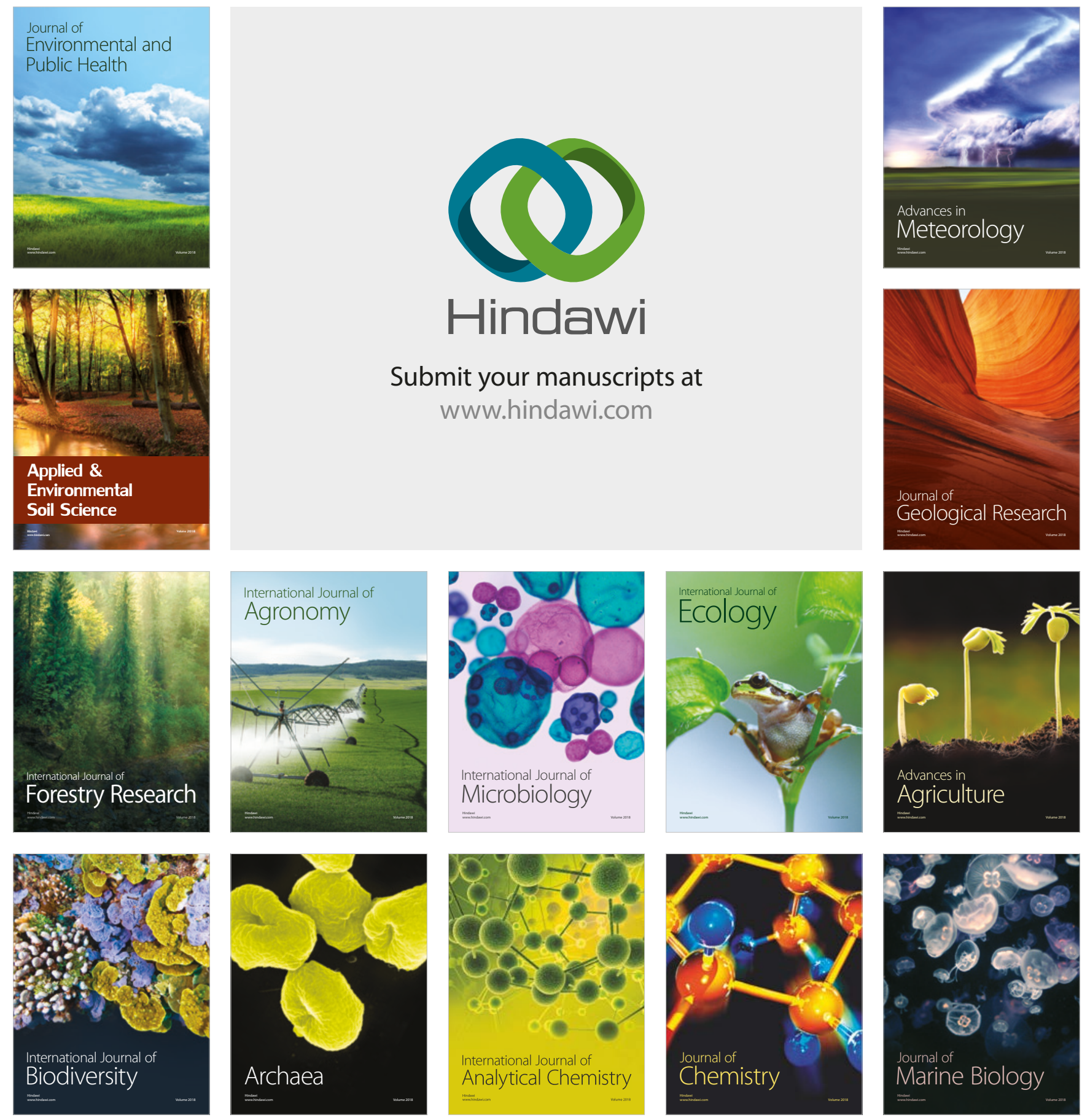